\title{
Low-frequency adaptation and recovery effects for lingual vibrotactile thresholds
}

\author{
KAL M. TELAGE and PETER J. GORMAN \\ Ithaca College, Ithaca, New York
}

\begin{abstract}
Lingual vibrotactile threshold adaptation and recovery effects were investigated. Three minutes of continuous vibrotactile stimulation preceded each of three experimental threshold trials. During recovery, three threshold trials followed rest periods of $1.5,3.0$, and $4.5 \mathrm{~min}$. A control group performed the same tasks with no adaptor stimulus. The experimental subjects showed significant threshold decay from baselines, with subsequent recovery. The control subjects' thresholds remained consistent with baselines. Implications for clinical oral sensory integrative testing are presented.
\end{abstract}

The threshold response characteristics of cutaneous tissues to conditioning vibratory stimuli have been widely studied. Increases in the absolute threshold for vibration, following intense stimulation and subsequent recovery functions across time, are documented in the literature (Cohen \& Lindley, 1938; Wedell \& Cummings, 1938). Recovery times ranged from approximately $9 \mathrm{~min}$ (Wedell \& Cummings, 1938) to 2-3 min (Berglund \& Berglund, $1970)$ and are apparently not greatly affected by the intensity of the conditioning stimulus. Other investigators have recorded changes in the subjective magnitudes of suprathreshold stimuli (Berglund \& Berglund, 1970; Gescheider \& Wright, 1968, 1969; Hahn, 1966, 1968; von Békésy, 1959).

Vibratory stimuli have been used by speech scientists to study the nature of sensory-neural receptor systems in lingual tissues. Some of these investigations have been primarily concerned with identifying integrative processing characteristics of the tactile feedback modality (Blackmon, McCaffrey, \& Fucci, 1983; Telage, Fucci, \& Blackmon, 1976; Telage \& Scott, 1980; Telage \& Warren, 1977). The rationale underlying this work is that integrative processing may more clearly identify impaired neurologic feedback that is essential to motor speech control. Although threshold adaptation is recognized as a method for detecting normal and impaired sensory processing at integrative levels, it has not been investigated for the lingual-tactile feedback system.

The purpose of this controlled study was to determine whether lingual vibrotactile thresholds for normal speaking subjects would increase subsequent to an intense conditioning stimulus. The study was also designed to measure subsequent recovery functions over prescribed time intervals. Findings would be relevant to a number of areas. First, adaptation for normal nonneurologically im-

\footnotetext{
The authors' mailing address is: School of Allied Health, Department of Speech-Language Pathology and Audiology, Ithaca College, Ithaca, NY 14850.
}

paired speaking subjects would provide normative data for threshold shifts that could then be compared with adaptation effects obtained from selected speech-defective groups. Second, the observation or pattern of adaptation would provide information concerning the nature of neural transducers mediating the lingual vibrotactile response. Third, the results would provide data for comparing the better known adaptation characteristics of cutaneous receptors with those found in mucal tissues.

\section{METHOD}

\section{Experimental Design}

It is essential to point out that mucal tissue like the tongue has not been investigated regarding sensory adaptation effects, whereas this phenomenon has been well researched for cutaneous tissue. The methodology used in this study required different instrumentation and was constrained by the use of frequency and intensity parameters that fall in the range of the tongue's vibrotactile detectability (Telage \& Gorman, 1985). The purpose of the research is to identify lingual adaptation phenomena that add to information about the tongue in particular and that may be generalized only to mucal tissues. Any assessment of the methodology or the reported findings must be made in this context.

The general design of this investigation is shown in Table 1. Testing conditions included both an experimental and a recovery phase. The experimental phase included determination of baseline lingual vibrotactile thresholds and presentation of three conditions. Condition A required $3 \mathrm{~min}$ of continuous stimulation on the tongue by a $10-\mathrm{Hz}$ adapter stimulus. This was followed by Condition $\mathrm{B}$, determining a lingual vibrotactile threshold at $50 \mathrm{~Hz}$. Condition $\mathrm{C}$ required a 3-min rest period, after which Conditions A, B, C, A, and B were repeated.

Stimulus adaptation was measured as a function of diminished lingual vibrotactile threshold sensitivity and is reflected by the three trials of Condition B. The recovery phase included three successive $50-\mathrm{Hz}$ lingual thresholds, Condition E, obtained subsequent to three different rest intervals: Condition D, $1.5 \mathrm{~min}$; Condition F, $3 \mathrm{~min}$; and Condition G, 4.5 min. Stimulus recovery was measured as a function of increased threshold sensitivity to the $50-\mathrm{Hz}$ stimulus and is reflected by the three trials of Condition E.

The study was controlled to ensure that threshold alterations from baseline were the result of a sensory adaptation and not a testing artifact. For this reason, the control subjects experienced all conditions except the $10-\mathrm{Hz}$ continuous stimulus. In addition, the experimental phase included Condition C, a 3-min rest between threshold determinations to reduce possible sensitivity alterations due to fatigue.

We view the procedure as a pilot model which, with additional research 
Table 1

Individual Vibrotactile Thresholds for Experimental and Control Subjects for All Conditions

\begin{tabular}{|c|c|c|c|c|c|c|c|c|c|c|c|}
\hline & \multicolumn{6}{|c|}{ Experimental Subjects } & \multicolumn{5}{|c|}{ Control Subjects } \\
\hline & la & $2 \mathrm{a}$ & $3 a$ & $4 a$ & $5 a$ & $6 a$ & $1 \mathrm{~b}$ & $2 \mathrm{~b}$ & $3 b$ & $4 b$ & $5 \mathrm{~b}$ \\
\hline \multicolumn{12}{|c|}{ Experimental Conditions } \\
\hline Baseline Threshold & 4.4 & 3.3 & 3.4 & 5.7 & 4.9 & 4.1 & 4.1 & 4.1 & 7.6 & 4.1 & 4.1 \\
\hline $\begin{array}{l}\text { A. } 10-\mathrm{Hz} \text { Stimulus* } 3 \text { Min } \\
\text { B. } 50-\mathrm{Hz} \text { Threshold Trial } 1 \\
\text { C. } 3-\mathrm{Min} \text { Rest }\end{array}$ & 8.6 & 7.3 & 11.6 & 11.0 & 14.2 & 12.8 & 4.1 & 5.1 & 8.0 & 6.0 & 4.1 \\
\hline $\begin{array}{l}\text { A. } 10-\mathrm{Hz} \text { Stimulus } \\
\text { B. } 50-\mathrm{Hz} \text { Threshold Trial } 2\end{array}$ & 10.0 & 6.2 & 11.9 & 11.6 & 14.7 & 12.8 & 4.1 & 4.2 & 6.3 & 5.8 & 4.1 \\
\hline C. 3-Min Rest & & & & & & & & & & & \\
\hline $\begin{array}{l}\text { A. } 10-\mathrm{Hz} \text { Stimulus* } \\
\text { B. } 50-\mathrm{Hz} \text { Threshold Trial } 3\end{array}$ & 11.4 & 7.3 & 13.2 & 11.2 & 12.5 & 11.6 & 4.1 & 5.8 & 8.3 & 5.3 & 4.1 \\
\hline \multicolumn{12}{|c|}{ Recovery Conditions } \\
\hline $\begin{array}{l}\text { D. 1.5-Min Rest } \\
\text { E. 50-Hz Threshold Trial } 1 \\
\text { F. 3-Min Rest }\end{array}$ & 6.6 & 7.7 & 12.6 & 11.3 & 12.2 & 12.4 & 4.1 & 6.1 & 7.7 & 4.9 & 4.1 \\
\hline $\begin{array}{l}\text { F. 3-Min Rest } \\
\text { E. 50-Hz Threshold Trial } 2 \\
\text { G. 4.5-Min Rest }\end{array}$ & 5.9 & 5.0 & 13.4 & 9.1 & 13.4 & 6.5 & 4.1 & 5.8 & 7.4 & 4.8 & 4.1 \\
\hline $\begin{array}{l}\text { G. 4.5-Min Rest } \\
\text { E. } 50-\mathrm{Hz} \text { Threshold Trial } 3\end{array}$ & 6.4 & 3.6 & 12.0 & 9.5 & 14.4 & 7.0 & 4.1 & 6.0 & 7.5 & 4.0 & 4.1 \\
\hline
\end{tabular}

*Instrument turned off for control subjects.

and development, can be modified and expanded into a more definitive diagnostic technique. A block diagram of the instrumentation package and a representation of the vibrotactile stimulator are presented in Figures 1 and 2.

\section{Experimental Procedures}

Eleven normal young adults were randomly selected and divided into an experimental group $(N=6)$ and a control group $(N=5)$. Prior to the experiment, all subjects were trained to provide reliable lingual vibrotactile thresholds. During testing, each was comfortably reclined in a motorized dental lounge that was adjusted to allow easy access of the tongue to the vibrator apparatus.

All subjects were required to press their tongues against the surround disk during the experimental and control conditions. The probe and contactor extended through an opening in the surround disk and were statically lowered $1 \mathrm{~mm}$ into the midline surface of the tongue prior to administering any stimuli.

The experimental subjects were presented with the $10-\mathrm{Hz}$ continuous adaptor stimulus at an intensity level of $150 \mathrm{mV}$ of peak displacement.
The $50-\mathrm{Hz}$ pulsed threshold-producing stimulus had a $50 \%$ duty cycle (on $1 \mathrm{sec}$, off $1 \mathrm{sec}$ ) with a rise/fall time of $100 \mathrm{msec}$. It was initially presented at an intensity of $100 \mathrm{mV}$ and was automatically attenuated in 5-mV increments per pulse until threshold was attained. Each threshold was determined using a one-trial descending psychophysical method of limits, which required about $1 \mathrm{~min}$ to complete. Data were initially obtained in millivolts of peak displacement and were converted to microns using an acceleration formula. A block diagram of the instrumentation package and a representation of the vibrotactile apparatus are presented in Figures 1 and 2.

\section{RESULTS AND DISCUSSION}

Means and standard deviations for all vibrotactile thresholds are presented in Table 2 . The mean baseline threshold for the experimental group was $3.8 \mu$, with $S D=0.8 \mu$. The mean baseline threshold for the con-

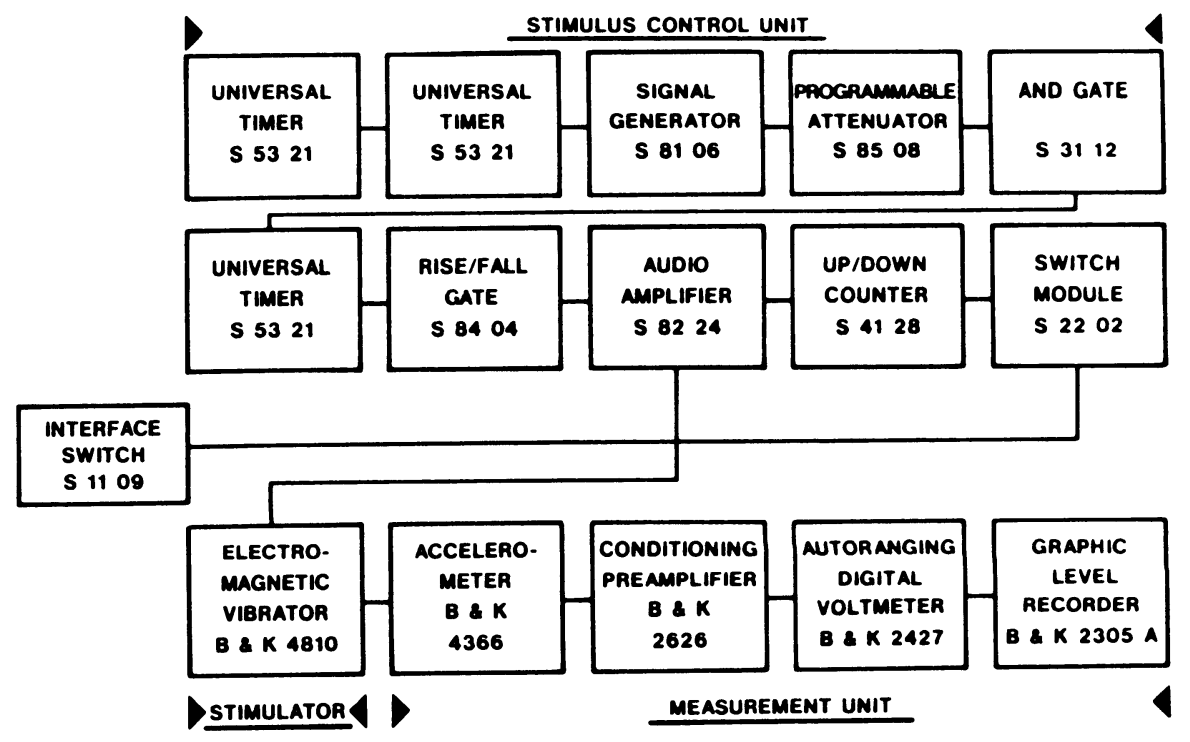

Figure 1. A block diagram of the instrumentation system. 


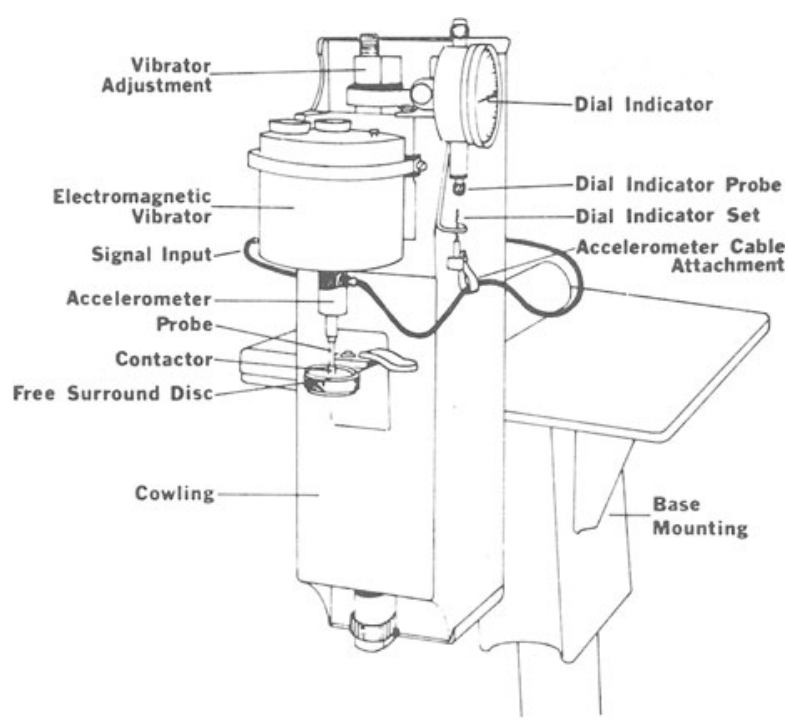

Figure 2. A schematic diagram of the oral vibrotactile stimulator.

trol group was $4.8 \mu$, with $S D=1.8 \mu$. The slightly higher average threshold and the standard deviation observed for the control subjects occurred due to 1 control subject's spurious threshold of $7.6 \mu$. In fact, the remaining 4 control subjects had the same threshold $(4.1 \mu)$. Table 1 presents the raw data from which means and standard deviations were determined.

Mean threshold data for the experimental group are observed during the three trials for Condition B. There is a clear threshold shift from a mean baseline of $3.8 \mu$ to respective mean thresholds of $10.9,11.2$, and $11.2 \mu$. The shift is indicative of diminished lingual sensitivity, which appeared to peak after 3 min of continuous stimulation with the $10-\mathrm{Hz}$ adaptor signal.

The raw data in Table 1 show that the individual adapted thresholds are consistent and approximately two to three times less sensitive than the baseline threshold values. Experimental Trials 2 and 3 did not result in any appreciable decrease in lingual sensitivity compared to Trial 1. This may have occurred because of Condition $\mathrm{C}$, which required a 3-min rest period following Condition $B$. This rest period was required for all subjects to minimize any sensitivity loss due to fatigue from maintaining the tongue in the test position. It is possible that Condition $\mathrm{C}$ may have allowed for some sensory recovery for the second and third experimental thresholds, and this may have reduced the overall cumulative adaptation effects for the experimental subjects.

Mean vibrotactile thresholds for the control group are presented in Table 2. The control trials for Condition B resulted in vibrotactile thresholds that are essentially the same as those observed for baseline. There is no indication of a threshold shift reflecting any diminished sensitivity for the controls. The raw data in Table 1 show that Control Subject $3 b$ consistently produced thresholds slightly higher than those observed for the other controls.
Means and standard deviations for vibrotactile thresholds obtained during recovery, Condition E, are presented for all subjects in Table 2. The first threshold trial was preceded by Condition D, 1.5 min rest; the second by Condition F, 3 min rest; and the third by Condition $\mathrm{G}, 4.5 \mathrm{~min}$ rest.

Although the experimental group showed a relatively fast adapting threshold response, the recovery pattern appeared to be a slow one. Condition $\mathrm{E}$ shows a mean increase in sensitivity of only $0.8 \mu$ after $1.5 \mathrm{~min}$. The recovery function peaked after Trial 2 with a mean increase in sensitivity of $2.4 \mu$. Mean threshold sensitivity did not increase over the next $4.5 \mathrm{~min}$ and remained $5.0 \mu$ above the mean baseline threshold. The slow recovery function is even more obvious from the raw data in Table 1 . Experimental Subjects 3a and 5a showed essentially no sensory recovery at all. Only one subject, $2 \mathrm{a}$, showed recovery consistent with the preconditioning baseline threshold. This general variability is reflected by the relatively large standard deviations for the three trials in Condition $\mathrm{E}$.

Within the design and selected parameters used in this study, the results support the conclusions that the lingual adaptation response below $60 \mathrm{~Hz}$ is fast adapting with a slow recovery function.

The non-Pacinian (NP) adaptation pattern is consistent with the presence of a NP receptor system mediating the vibrotactile response in the mucal tissues of the tongue's surface. There is general agreement on this point; it has been presented in the literature by Winkelman (1960), who considers that it is the system mediating vibration for the mucal tissues of the dorsal lingual surface.

Future research in lingual adaptation may provide more definitive information regarding the question of receptor systems in the tongue's surface by investigating this response in the Pacinian (P) system's frequency range. A nonadaptation effect would support the presence of a $P$ receptor transducing system in the tongue's surface tissues. Adaptation in this same frequency range would be consistent with a sole NP response.

Other research is needed to identify normal lingualtactile adaptation characteristics within a range of low to high frequencies. This kind of data would reflect a more

Table 2

Means and Standard Deviations in Microns of Peak Displacement for Oral Vibrotactile Thresholds Obtained from the Tongue

\begin{tabular}{|c|c|c|c|c|c|c|c|}
\hline & \multirow{2}{*}{$\begin{array}{l}\text { Baseline } \\
\text { Thresholds }\end{array}$} & \multicolumn{3}{|c|}{$\begin{array}{l}\text { Experimental Trials for } \\
\text { Vibrotactile Thresholds } \\
\text { Condition B }\end{array}$} & \multicolumn{3}{|c|}{$\begin{array}{l}\text { Recovery Trials for } \\
\text { Vibrotactile Thresholds } \\
\text { Condition E }\end{array}$} \\
\hline & & 1 & 2 & 3 & 1 & 2 & 3 \\
\hline \multicolumn{8}{|c|}{ Experimental Group } \\
\hline Mean & 3.8 & 10.9 & 11.2 & 11.2 & 10.4 & 8.8 & 8.8 \\
\hline SD & 0.8 & 2.5 & 2.8 & 2.0 & 2.7 & 3.7 & 3.8 \\
\hline \multicolumn{8}{|c|}{ Control Group } \\
\hline Mean & 4.8 & 5.4 & 4.9 & 5.4 & 5.3 & 5.2 & 5.1 \\
\hline SD & 1.8 & 1.6 & 1.0 & 1.7 & 1.4 & 1.3 & 1.5 \\
\hline
\end{tabular}


complex level of sensory processing than is currently determined by sensation level vibrotactile thresholds. Such data may increase knowledge concerning the interplay of sensory-motor interactions in motor speech control and, thus, allow for elaboration of current models.

\section{REFERENCES}

Berglund, U., \& Berglund, B. (1970). Adaptation and recovery in vibrotactile perception. Perception \& Motor Skills, 30, 843-853.

Blackmon, R. C., McCaffrey, P., \& FucCI, D. J. (1983). Effect of lingual vibrotactile stimulation on the averaged cortical evoked response. Perception \& Motor Skills, 57, 383-389.

CoHEN, L. H., \& LindLeY, S. B. (1938). Studies in vibratory sensibility. American Journal of Psychology, 51, 44-63.

Gescheider, G. A., \& WRIGHT, J. H. (1968). Effects of sensory adaptation on the form of the psychophysical magnitude function for cutaneous vibration. Journal of Experimental Psychology, 77, 308-313.

GescheIDER, G. A., \& WRIGHT, J. H. (1969). Effects of vibrotactile adaptation on perception of stimulus of varied intensity. Journal of Experimental Psychology, 81, 449-453.

HAHN, J. F. (1966). Vibrotactile adaptation and recovery measured by two methods. Journal of Experimental Psychology, 71, 655-658.
HaHN, J. F. (1968). Low-frequency vibrotactile adaptation. Journal of Experimental Psychology, 78, 655-659.

Telage, K. M., Fucci, D. J., \& Blackmon, R. (1976). Temporal summation effects on lingual vibrotactile thresholds. Perception \& Motor Skills, 42, 859-864.

Telage, K. M., \& GoRman, P. J. (1985). An investigation of lingual vibrotactile detectability. Bulletin of the Psychonomic Society, 23, 50-52.

TelaGe, K. M., \& ScotT, J. C. (1980). Effects of auditory interference upon observed lingual tactile thresholds. Bulletin of the Psychonomic Society, 15, 422-424.

Telage, K. M., \& Warren, J. (1977). Spatial summation effects on lingual vibrotactile thresholds. Perception \& Motor Skills, 44, 1179-1185.

VON BÉKÉSY, G. (1959). Synchronism of neural discharges and their demultiplication in pitch perception on the skin and in hearing. Journal of the Acoustical Society of America, 31, 338-349.

Wedell, C. W., \& Cummings, S. B. (1938). Fatigue of the vibratory sense. Journal of Experimental Psychology, 22, 429-438.

Winkelman, R. K. (1960). Nerve endings in normal and pathologic skin. Springfield: Thomas.

(Manuscript received for publication September 12, 1985.) 